\title{
National Representation without Citizenship: the Special Case of Rugby
}

\author{
DANYEL REICHE
}

\section{sciendo}

Politics in Central Europe (ISSN: 1801-3422)

Vol. 17, No. 3

DOI: 10.2478/pce-2021-0021

\begin{abstract}
This article is a case study of one of the few sports, rugby, that does not link national representation exclusively to citizenship. It discusses who may represent a country in major events and under which conditions. It analyses the consequences of the rules on different stakeholders; and discusses why the residency rule in particular is subject to much controversy. The author has conducted case studies of the 2019 rugby union and 2017 rugby league men's World Cups. Academic literature, international newspapers, and rugby-specific websites were reviewed. Other than secondary sources, the researcher also collected primary data through interviews. The interviewees included representatives of Rugby League International Federation and World Rugby. This research reveals that national representation without citizenship is widespread in both codes of rugby. It has also shown that the effects of the eligibility criteria go beyond simplistic rich/poor and center/periphery models. This article argues that the rational for the eligibility criteria is the limited global spread of rugby league and rugby union. Without those lenient rules it would be difficult to organize international competitions.
\end{abstract}

Keywords: citizenship; eligibility criteria; rugby league; rugby union; residence; sports governance.

\section{Introduction}

This article argues that contemporary practices used for defining the eligibility criteria to represent a country in rugby are a product of the history of the game and date back to the late $19^{\text {th }}$ century. The rational for maintaining the same eligibility criteria throughout the years has shifted from a shared British imperial identity to the objective of globalizing the game. However, the main 
pillars of the rules have remained stable over a period of more than 100 years with only minor adjustments being made.

Rugby union is one of the most popular team sports in the world, particularly in Commonwealth countries. According to World Rugby, the men's Rugby World Cup 2019 in Japan was the most watched rugby event ever. The global cumulative viewing figures for the tournament grew from 679 million in 2015 to 851 million in 2019. The final between England and South Africa was the most-watched sports event of 2019 in the UK (World Rugby 2019). This championship is not only remembered because of the final with a win by the South African team, but also for controversy over citizenship of the players. A topic that caused heated debates among rugby fans was the fact that almost one in four players $(23 \%)$ at the World Cup did not hold a passport from the country they represented. Not only did second-tier rugby union countries rely on athletes with foreign passports, notably even one of the teams in the finals, England, was represented by a significant proportion of players (around $20 \%$ ) without English citizenship (see table 2).

There are two forms (or as rugby fans call them, 'codes') of rugby: rugby union, which is globally far more popular, and rugby league, which has its strongholds in the north of England and two Australian states, Queensland and New South Wales. Rugby league developed in the late nineteenth century in Northern England as 'part of the symbolism of northern working-class history and identity'. The game separated in 1895 from rugby union due to a dispute over amateurism, which was advocated for by the upper-class rugby union community, versus professionalism (Collins 2012: 119). Over time, league and union developed into distinctive versions of the sport with rugby league teams comprised of fewer players (13 instead of 15) who played by slightly different rules. Before 1995, rugby union was not played as a professional sport as opposed to rugby league which had achieved this characteristic of paying its players a 100 years earlier. In spite of these differences there are also similarities between both versions of rugby such as the eligibility criteria for national representation in international sporting events. Non-citizenship holders can represent countries based on either ancestry or residence. Notably, at the 2017 rugby league men's World Cup in Australia, New Zealand, and Papua New Guinea there were national teams which consisted wholly of players who lacked citizenship of the countries they represented at the tournament. Most of these players were in fact Australians, making the World Cup a pseudo-competition between Australian 'A' and 'B' teams in the view of some commentators (Gorman 2017).

Sporting events where entire teams can be comprised of athletes from different countries have become renowned. Examples include national leagues, multinational club competitions such as the UEFA Champions League (soccer), or the cycling race Tour de France, in which a diverse group of individuals of several nationalities form a team that is sponsored by and named after corpo- 
rations. When it comes to more traditional international sporting events such diversity, however, is not the norm. This does not mean that there are only 'pure' national teams. Sport-specific naturalisations have been on the rise especially in the Middle East (Reiche - Tinaz 2018). There are also dual nationals on many national teams. What these naturalised or dual/multi-national athletes have in common is that they are often labelled as 'mercenaries' (Bohland 2017). However, these athletes typically need to fulfil the formal requirement set forth by international sports governing bodies that they must hold citizenship of the country they represent at the tournament.

Rugby league and rugby union, on the contrary, belong to a small group of sports that allow athletes to represent a country of which they are not citizens. There are only few sports that have similar rules to rugby league and rugby union: According to a review conducted by the author of the article of all the sports included in the current Olympic as well as the current Commonwealth Games programs, cricket and squash have a residence requirement of three years for an athlete to represent a country. In netball and bowls, the threshold is even lower and athletes qualify for national representation by residing in a country for a period of 24 months prior to the start of the relevant international event (International Cricket Council 2018: 5; International Netball Federation 2016: 5; World Bowls 2018: 4; World Squash Federation 2019: 15). Interestingly, of the aforementioned games with distinct rules for national representation, rugby is the only sport listed in the Olympics. Other sports are only included in the Commonwealth Games program. This is, however, a recent turn of events as rugby only returned in 2016 to the Olympic program after being absent from the Games for 92 years.

\section{Literature review}

Academic literature on citizenship, nationality and migration issues in sport has mainly dealt with sport labor migration (see, for example, Bale - Maguir 2013; Schroeder - Janssen 2012). There is extensive discussion on the motivations for players to move from one country to another, including both economic and non-economic reasons (in the latter regard particularly having the opportunity to represent a country in international sports). There is a broad body of academic literature discussing how the internationalization of sports affects national identities and to what extent sporting immigrants assimilate into their new country (Cronin - Mayall 1998; Dolon - Connolly 2016; Johnes 2000; Maguire Tuck 1998; Poli 2007). Recently, the interest of academic literature has shifted from sociological towards legal and political aspects of sport labor migration by discussing the eligibility criteria in international sport (Exner 2019; Reiche 2019), the legal framework for dual nationals in international sporting events (Bohland 2017; Jansen et al. 2018; Spiro 2016) and the role that naturalisation 
of foreign athletes play at the Olympic Games (Horowitz - McDaniel 2015; Jansen - Engbersen 2017; Jansen et al. 2018; Reiche - Tinaz 2018).

Some books and articles on migrant athletes in both codes of rugby relate to this work as well. Collins (2009), in A Social History of English Rugby Union, refers to early discussions on eligibility criteria in rugby union's world governing body and presents several examples of nationality transfers and dual representation of countries in international competitions in the late nineteenth and early twentieth centuries. Harris (2010), in his book Rugby Union and Globalization, looks at player migration since the sport became professional in 1995 and at what he calls 'passports of convenience', referring to players who represent nations other than their countries of birth. Overton et al. (2013) in their article 'Pass the passport' provide data on foreign athletes in national squads at the 2011 rugby union men's World Cup. Grainger et al. (2014) discuss the one-country-for-life rule in rugby union and its implications, particularly for athletes from the Pacific Islands.

Most journal articles look at specific 'player-sending' countries, such as the Pacific Islands, or particular 'player-receiving' nation-states, like Japan, and at how the eligibility criteria have affected these states. Most work has been conducted on rugby union, reflecting the larger popularity of this code of rugby. Horton (2012) looks at the role of Pacific Islanders in global rugby union while Kanemasu and Molnar (2012) as well as Guinness and Besnier (2016) specifically focus on players emigrating from Fiji and their experiences in their new home nations. Grainger (2006) discusses the role of Samoan players in New Zealand and how they transcend national identity in their new home country. Pienaar and Koch (2012) explore the motives of South African players to migrate to other countries. Sakata (2004) investigates the influence of foreign athletes on the development of the Japanese national team and Japanese clubs. Chiba and Jackson (2006) focus specifically on the immigration of players from New Zealand to Japan.

While most academic articles are on rugby union, there are also two papers on rugby league. Lakisa et al. (2014) discuss the influence of Pacific Islanders on Australian rugby league, and Reiche (2019) discusses the role of Australians of Lebanese heritage in the Lebanese national rugby league men's team at the 2017 rugby league World Cup.

\section{Methodology}

This article is a case study of one of the few sports that does not link national representation exclusively to citizenship. It discusses who may represent a country in major events and under which conditions. This research will explore the historical roots of rugby league's and rugby union's eligibility criteria, compare them, and discuss recent modifications such as the one-country-for-life rule in 
rugby union. The author has researched as case studies the 2019 rugby union and 2017 rugby league men's World Cups, examining the extent and conditions under which athletes without citizenship represented participating countries. The motives of World Rugby and the Rugby League International Federation (RLIF) for maintaining the eligibility criteria are discussed, and the consequences for different stakeholders such as governments, international and national federations, players, and fans are presented. As a final step of the research, the paper discusses why the residency rule in particular is subject to controversy.

Academic literature, international newspapers, and rugby-specific websites were reviewed. Many articles on foreign athletes on national teams were published around major events, such as the 2019 rugby union and the 2017 rugby league World Cups and the times during which World Rugby (rugby union) and Rugby League International Federation (RLIF) reviewed their eligibility criteria. Instances include the one-country-for-life rule introduced in 2000 and the 2017 decision to extend the residence requirement from three to five years for players in rugby union.

Other than secondary sources, the researcher also collected primary data through six interviews, all of which were conducted in 2018, 2019, and 2020. Most sources were interviewed on more than one occasion. The researcher interviewed a leading historian on both codes of rugby, a scholar who authored a book on the globalisation of rugby union, the Global Operations Manager of the Rugby League International Federation, a former press officer of World Rugby who also helped the author access the archive of the organisation to review the first meeting notes of the International Rugby Board (formed in 1886) dealing with discussions on eligibility criteria, the secretary general of the German rugby union federation, and a French player on the Lebanese rugby union national team.

The main purpose of the interviews was to learn the respondents' knowledge and views on the historical development and rationale of the eligibility criteria in both codes of rugby as well as to understand the consequences for different stakeholders. The chosen format of asking a series of open-ended questions allowed for more fluid interactions between the researcher and respondent and provided a multi-perspective understanding of the topic by not limiting respondents to a fixed set of answers (Bryman 2012: 470).

\section{Eligibility criteria in both codes of rugby in comparison}

As in other sports, citizenship qualifies players in both codes of rugby to represent a country. However, in rugby union and rugby league, unlike other sports, citizenship is not the sole criterion that enables participation within a national team. There are two other options: proof of ancestry (defined as citizenship of parents or grandparents) or proof of residence. The latter is defined by World 
Rugby as a 'sporting naturalisation procedure, based on a geographical/presence test' (World Rugby 2016:163). These eligibility criteria apply to both male and female players.

Table 1 presents a comparative overview of the eligibility criteria in both codes of rugby. It shows that the residence requirement was previously set at three years in both codes before rugby league decided in 2016 to increase this period to five years. Rugby union finally did the same in 2017 by announcing that a residency requirement of 60 months will take effect from December 31, 2020. Considering the exceptional circumstances posed by the COVID-19 pandemic, World Rugby decided in August 2020 to postpone the introduction of the five years residence rule by one year to December 31, 2021 (World Rugby 2020). This means that players who switch national allegiance must skip at least one World Cup as the event is held every four years in both codes of rugby. Both codes of rugby have different definitions of what residence means. In rugby union a physical presence of at least 10 months per year in a country is required. Rugby league rules are a little bit more lenient in that they set a minimum requirement of 210 days, or approximately seven months per year.

Both codes of rugby have not imposed any restrictions on naturalised players. In soccer, naturalised players need to live at least five years in their new home countries after their eighteenth birthday before FIFA accepts players' naturalisations. This strict rule was slightly modified in 2020: 'The new wording of FIFA's regulations means that as well as living somewhere for five years after the age of 18, players who started living in a country before the age of 10 can be eligible after living there for three years, and those who started living there after the age of 10 can be eligible after five years' (Price 2020). Rules in basketball are even more strict i.e., the number of naturalised players on a national team is limited to only one athlete that can have obtained nationality after the age of 15 . An unlimited number of players can be naturalised in rugby league and rugby union and they can start playing for a national team on the same day that they receive their new passport (RLIF 2016).

While eligibility criteria in rugby league and rugby union are quite similar, apart from the aforementioned stricter rule on physical presence for fulfilling the residence criteria in rugby union, one major difference between the codes concerns the rules for switching national allegiances. Since January 2000, players have to commit for life to a national team in rugby union. Once they have played even a single match for a 15-a-side or rugby sevens senior national team, they can no longer represent another country. This means, for example, that an Australian player with roots in the Pacific Islands who at the age of 18 was nominated only once to play for the Wallabies, but was never nominated again, cannot play later in life for Samoa or Tonga, even if (s)he has moved back to the islands and fulfilled the residence or ancestry criterion for World Rugby eligibility. Before the year 2000, nationality transfers were possible after 
a waiting period of 36 months since the last representation of another country. According to World Rugby, 'the one Union only rule is designed to maintain the integrity of the international Game' (World Rugby 2016: 159). To sum up, rugby union is lenient in defining nationality, but quite strict when it comes to maintaining loyalty to a country. In contrast, rugby league's rules are lenient when it comes to loyalty. Nationality transfers are only restricted within the narrowly defined group of Tier 1 countries which includes only Australia, England, and New Zealand. The RLIF rules state, 'A Player is entitled to move between a Tier 1 and a Tier 2 or Tier 3 Nation freely save that a Player may not change their National Team during any RLIF Global Event' (RLIF 2016).

Rugby rules in the Olympic differ significantly from the rules for rugby in world championships and other international tournaments. The 15-a-side version of rugby union was only included for men's teams in the Olympic program in the early editions of the Games in 1900, 1908, 1920, and 1924. In 2016, rugby union returned to the Olympic stage in its seven-a-side version with both men's and women's competitions. For Olympic competitions, World Rugby, like other international federations, has to respect the rules of the International Olympic Committee (IOC). The IOC eligibility criteria differ from the World Rugby rules by strictly requiring citizenship for national representation, but allowing nationality transfers. The Olympic Charter states that 'any competitor in the Olympic Games must be a national of the country of the NOC which is entering such competitor' (IOC 2018: 60). Regarding switching national allegiance, the IOC charter states that:

A competitor who has represented one country in the Olympic Games, in continental or regional games or in world or regional championships recognised by the relevant IF, and who has changed his nationality or acquired a new nationality, may participate in the Olympic Games to represent his new country provided that at least three years have passed since the competitor last represented his former country. This period may be reduced or even cancelled, with the agreement of the NOC and IF concerned, by the IOC Executive Board, which takes into account the circumstances of each case (IOC 2018: 80).

World Rugby decided to apply 'solely in respect of the Rio Olympic Games 2016, a stand down period of at least 18 months,' but wants to apply the IOC recommended stand down period of three years in future Olympic Games (World Rugby 2016: 55).

One effect of the difference in eligibility criteria of World Rugby and IOC was explained to the author in an interview with a French player who moved to Lebanon in 2015 and was nominated for the Lebanese rugby union 15's team for the first time in 2018: 'The coach already told me [he did] not [...] select me for the national rugby sevens side because they did not want to waste time 
with me since I could not play in the Olympics.' Unlike rugby union, rugby league is not included in the Olympic program and remains unrecognised by the International Olympic Committee. In January 2018 RLIF was granted Observer Status by GAISF (Global Association of International Sports Federations - formerly SportAccord), a first success in the struggle for international recognition.

What both rugby league and rugby union rules do not prohibit is the occasion of one player representing the same or different countries in different codes. Frano Botica and Sonny Bill Williams, for example, represented New Zealand both in rugby league and rugby union. Lesley Vainikolo represented New Zealand in rugby league before playing for the English national rugby union team. An article in The New York Times highlighted the case of Cooper Vuna, another player who represented two different countries in rugby league and rugby union. Vuna was born in New Zealand to a father who was a Tongan rugby union national player. Cooper Vuna was selected for New Zealand's pre-

Table 1: Eligibility criteria in both codes of rugby in comparison

\begin{tabular}{|c|c|c|}
\hline Criteria & Rugby union & Rugby league \\
\hline Citizenship & Yes & Yes \\
\hline Citizenship of parents & Yes & Yes \\
\hline Citizenship of grandparents & Yes & Yes \\
\hline Residence & $\begin{array}{l}\text { Yes ( } 3 \text { years, } 5 \text { years starting } \\
\text { December 31, 2021) }\end{array}$ & Yes ( 5 years) \\
\hline $\begin{array}{l}\text { Minimum requirements for } \\
\text { residence }\end{array}$ & $\begin{array}{l}\text { Physical presence of at least } 10 \\
\text { months }\end{array}$ & $\begin{array}{l}\text { A minimum of } 210 \text { days in the } \\
\text { preceding } 12 \text { months }\end{array}$ \\
\hline Change of national teams & $\begin{array}{l}\text { One-country-for-life rule for all } \\
\text { countries }\end{array}$ & $\begin{array}{l}\text { Possible; one-country-for-life } \\
\text { rule only within group of Tier } 1 \\
\text { countries }\end{array}$ \\
\hline $\begin{array}{l}\text { Restrictions for naturalised } \\
\text { players }\end{array}$ & $\begin{array}{l}\text { No, unless they already represent } \\
\text { one country }\end{array}$ & No \\
\hline $\begin{array}{l}\text { Change of codes and } \\
\text { countries possible }\end{array}$ & Yes & Yes \\
\hline Olympic Games & $\begin{array}{l}\text { Included in Olympic program } \\
\text { (rugby sevens). Different from } \\
\text { World Rugby competitions, } \\
\text { citizenship is required and } \\
\text { nationality transfers are possible } \\
\text { after a stand-down period of } \\
18 \text { months ( } 2016 \text { Olympics) and } \\
\text { accordingly } 3 \text { years (future } \\
\text { Olympics) }\end{array}$ & Not included in Olympic program \\
\hline
\end{tabular}

Sources: IOC 2018; RLIF 2016; World Rugby 2016; World Rugby 2020 
liminary squad for the 2008 Rugby League World Cup, but when he was not nominated for the tournament, he switched allegiance and played for Tonga at the 2008 world championship. After the tournament, he changed from rugby league to rugby union and started to play for an Australian club as well as the Australian national rugby union team. However, he was only nominated twice in 2012. Prior to the 2016 Summer Olympics, he benefitted from the relatively flexible IOC rules for nationality transfers (compared to those of World Rugby) and played in qualification matches for the rugby sevens national team from Tonga (Wigmore 2016).

\section{Results}

Both the 2019 rugby union men's World Cup, hosted by Japan from September 20 to November 2, 2019, and the 2017 rugby league men's World Cup, hosted by Australia, New Zealand, and Papua New Guinea between October 27 and December 2, 2017, relied heavily on players without. Almost one out of four players at the 2019 rugby union World Cup represented a country without holding its citizenship. As table 2 shows, 144 out of 620 players ( $23 \%$ ) did not hold such citizenship - $42 \%$ (60) of them could play based on the residence criteria and $58 \%$ based on some form of ancestry (68 based on their parents' and 16 based on their grandparents' citizenship).

Argentina, Namibia, and Uruguay participated as the only countries with a foreigner-free squad while Tonga, Samoa, Japan and Scotland had between 15 and 19 of their players without citizenship. Interestingly, rugby union powerhouses like Australia (12) also had a high number of foreigners on their teams (see table 2).

When looking in detail at these countries, it is obvious that economically stronger countries with professional rugby union leagues, such as Australia and Japan, mainly benefitted from the residency rule while less developed countries with a lack of domestic employment opportunities and large diasporas, such as Samoa and Tonga, benefitted mostly from the parents' ancestry rule. The significance of the grandparents' ancestry rule is minor, only having some importance for Scotland which had seven players as part of its team that fulfilled the ancestry rule for eligibility of participation.

Although for the 2017 rugby league World Cup there is less accurate data available compared to the 2019 rugby union World Cup, clear trends can be identified based on the researcher's interview with a RLIF representative. According to the interviewed RLIF global operations officer, the federation has a player but not a team-based database: 'We have every player's eligibility on file, but we do not have a document that logs how many players in each 23-man squad were born abroad. We would have to check every player manually.' Rugby league is at least as reliant on foreign players as rugby union, but, according 
Table 2: Players without citizenship at 2019 Rugby union World Cup by eligibility criteria

\begin{tabular}{|c|c|c|c|c|}
\hline Country & $\begin{array}{l}\text { Number of players without } \\
\text { national passport/total } \\
\text { number of players }\end{array}$ & Grandparents & Parents & Residence \\
\hline Tonga & 19 & 0 & 19 & 0 \\
\hline Samoa & 18 & 1 & 17 & 0 \\
\hline Japan & 16 & 0 & 1 & 15 \\
\hline Scotland & 15 & 7 & 6 & 2 \\
\hline USA & 13 & 2 & 5 & 6 \\
\hline Australia & 12 & 0 & 0 & 12 \\
\hline Italy & 8 & 2 & 3 & 3 \\
\hline Wales & 8 & 1 & 4 & 3 \\
\hline Ireland & 7 & 1 & 3 & 3 \\
\hline England & 6 & 1 & 1 & 4 \\
\hline France & 5 & 0 & 0 & 5 \\
\hline Canada & 5 & 1 & 2 & 2 \\
\hline Fiji & 4 & 0 & 4 & 0 \\
\hline New Zealand & 4 & 0 & 0 & 4 \\
\hline Russia & 2 & 0 & 2 & 0 \\
\hline South Africa & 1 & 0 & 0 & 1 \\
\hline Georgia & 1 & 0 & 1 & 0 \\
\hline Namibia & 0 & 0 & 0 & 0 \\
\hline Argentina & 0 & 0 & 0 & 0 \\
\hline Uruguay & 0 & 0 & 0 & 0 \\
\hline Total & $144 / 620$ & 16 & 68 & 60 \\
\hline
\end{tabular}

Source: Author's calculations based on Americas Rugby News 2019 
to the RLIF representative, there are certainly differences in the application of the eligibility criteria:

\begin{abstract}
As someone who has been involved in a lot of eligibility checks over the last few years, parentage is definitely more common in rugby league than residency due to the fact that there are fewer established professional clubs. So fewer places for top players to reside to meet the residency rule. You are on safe ground to say that rugby league is opposite to rugby union with the vast majority of players qualifying through the parent/grandparent rule, not residency.
\end{abstract}

There are (semi-)professional rugby league clubs in Australia, England, France, Papua New Guinea, and New Zealand: 'I doubt there is any non-Papuan professional playing and living in Papua New Guinea, so that reduces the number of countries where residency rule matters to just four nations.' According to the RLIF officer, a clear trend in the 2017 rugby league World Cup was that the rugby league powerhouses hardly relied on players without citizenship while second tier countries relied heavily on players without citizenship. Those players were mainly selected on the basis of their ancestry. He gave examples of the following four (out of 14 in the 2017 rugby league World Cup participating) national teams: 'France had one resident player and 22 French-born; England 22 English-born players and one player with ancestry claim. Lebanon and Italy had 23 players who qualified via ancestry rule.' 22 out of the 23 Lebanese players were living in Australia, which led some people to dub them as the Australian B team (Gorman 2017).

\title{
Reasons for eligibility criteria in both codes of rugby
}

History matters to understand the roots of the eligibility criteria in rugby league and rugby union. A certain path dependency has established 'a historical pattern where previous events set into motion self-reinforcing feedback mechanisms which considerably change the likelihood of subsequent events or outcomes' (Bengtsson 2012: 161). The trajectory of the current eligibility criteria in both codes of rugby dates back to the beginning of the game and the first international matches in the late nineteenth century; this particular history seems to keep decision-makers in both codes of rugby disinclined to change the rules.

According to the World Rugby archive, the international governing body of rugby union - at that time named the International Rugby Football Board discussed eligibility criteria for national representation at a meeting as early as July 1892, only six years after the Board's establishment in 1886 . The issue of JH Marsh, a centre with the Swindon club, was discussed. The Scottish Union wrote to the RFU to complain that Marsh, having already played for 
Scotland (in 1889), was then selected and played for England (in 1892). Because there was no rule to prohibit this, the IRFB asked the Unions to consider the adoption of a qualifying rule, 'birth qualification being in the opinion of the Board the most desirable.' Furthermore, the Board discussed the case of Colonials (players from NZ, Australia, and SA), who were residents in the UK. In their case, 'qualification should be by residence' (IRFB 1892). The Board also noted that 'no man should play for two countries,' although this was never enforced, and plenty of examples are known of players who played for more than one country.

'Interchangeable national identities had been a feature of the international game almost since its inception,' writes Collins in A Social History of English Rugby Union (Collins 2009: 163). The international rugby union federation 'refused to take any steps towards defining international qualifications,' and no action was taken to control the movement of players until the 1980s (Collins 2009: 164). The only exception was the 1898 ruling that no player could play for two home nations. The term 'Home Nations' herein refers to England, Scotland, Wales, and Northern Ireland (before partition in 1920, it referred to the whole of Ireland). According to Collins (2009: 164), 'it was the English who reaped the most benefit from overseas players'. The main reason for the attractiveness of England for foreigners were its universities, particularly the oldest and most prestigious universities in the country, Oxford and Cambridge.

The first rugby union World Cup was not held until 1987, while the first rugby league World Cup took place in 1954. The annual varsity match between the rugby union teams from Oxford and Cambridge universities has long been one of the highlights of global rugby union, and their inclusion in the game played at Rugby Football Union's home ground Twickenham stadium in London has always been one of the greatest honors in rugby union (Markovits - Rensmann 2010: 287). This event still enjoys popularity in the professional age of rugby union. For example, the 2018 game drew an attendance of 21,893 fans. Oxford won the men's game, which has been played since 1882, and Cambridge won the women's game, which celebrated its $30^{\text {th }}$ anniversary of inclusion in the event (The Varsity Game website).

Another reason for the eligibility criteria in both codes of rugby is that the two sports have never entirely gone global, unlike soccer and basketball. For Harris (2010: xiv), it is 'rugby's biggest challenge, to develop a truly global presence.' In Gaming the World: How Sports are Reshaping Global Politics and Culture, Markovits and Rensmann write that 'both rugby codes became the legacy of Britain's political power by occupying the sports spaces of countries that were directly governed by Britain as its colonies' (Markovits - Rensmann 2010: 63). Harris (2010: 18) notes, 'that English is the language spoken most widely in seven of the eight core nations in the game, with France being the exception to the norm in this regard, powerfully illustrates the roots of the game.' For 
Markovits and Rensmann (2010: 66), there are 'few notable exceptions like France, Argentina and in more recent times Italy, Romania, Russia, and Japan' as non-English speaking nations who compete in rugby tournaments. While rugby is, according to Markovits and Rensmann, soccer's 'closest relative', soccer became the more popular game in most countries due to its simplicity. The United States and Canada fall into the group of countries that did not adopt soccer as their primary hegemonic sport, but they 'transformed extant British games into North American sports that then blossomed into their own sports culture: rounders into baseball; rugby football into American (and Canadian) football; field hockey into ice hockey; and netball into basketball' (Markovits Rensmann 2010: 75).

This limited global spread and the desire to grow certainly explain why rugby league and rugby union are so lenient in their eligibility criteria. Without lax rules a country such as Lebanon would not be able to qualify for a rugby league World Cup, as it did twice in 2000 and 2017 (Reiche 2019). While there are 20 participating countries at the rugby union World Cup, there are 14 participating countries in the rugby league World Cup. Without the lax eligibility criteria, the events would be dominated by a few countries and a larger performance gap between participating countries would exist.

When interviewed for this work, the former press officer from World Rugby also emphasized that rugby union was an amateur sport until 1995: 'The comparable lax eligibility criteria were based on the concept of amateur rugby, a sport played by young men, and later on women, for sheer enjoyment. The idea was to allow the players to play where they stay.' He gave, amongst others, the example of Daniel Carroll who won the rugby union gold medal in 1908 when he played for the Australian team. After moving to the United States to pursue a degree at Stanford University, he started to play for the US national team and represented them at the 1920 Summer Olympic Games.

Apart from the long tradition of amateurism in rugby union, the presence of foreign students in England at Cambridge and Oxford (but also in Scotland at the University of Edinburgh); the mobility of players from England, Scotland, Wales, and Northern Ireland within the home nations; the limited global spread of rugby league and rugby union; and a shared British imperial identity are key explanations for the invention of the residency rule.

Looking back at the history of rugby league and rugby union helps to understand the reasons for the residency rule, however, the reasons behind the addition of the parent/grandparent rule remain unclear. When interviewed for this research, a leading rugby historian who has published extensively on the history of both codes said, 'I suspect that it derives from the British Imperial idea that emigrants and colonists who lived outside of Britain were still British, despite not having been born in Britain. It was not until the 1960s that people in Australia and New Zealand stopped referring to Britain as "Home."” 


\section{Discussion}

The architecture of international sports is, much like global politics, a system of nation-states. Nation-States define the precise character of citizenship which consequently affects the national sporting federations and selection of their athletes. 'Nation-states are the arbiters in determining who gets in and who does not' (Kivisto 2018: 425). A general power shift occurs, from the government to the national sporting federations, when an athlete, without citizenship, is allowed to compete for a country. The eligibility rules in World Rugby and RLIF allow national rugby league and rugby union federations some form of self-determination. Proof of residency along with ancestry rules in rugby league and rugby union reveal that issues of belonging have become a domain not exclusive to the nation-state only.

The inclusion of foreign passport holders into national teams can be linked to ideas of world citizenship and cosmopolitanism, defined by Kivisto as the 'idea of citizenship that moves beyond the nation state' (Kivisto 2018: 415). Markovits and Rensmann define cosmopolitanism as 'respect for strangers and the universal recognition of individuals independent of their cultural or racial background, citizenship, and heritage' (Markovits - Rensmann 2010: 2). Hence, despite different passports, all players in a tournament are interconnected by their mutual participation in and passion for the same game. However, even with the lenient rules in both codes of rugby, there are still boundaries drawn between insiders and outsiders, based on the membership rules (eligibility criteria) of the international federations. As Spiro points out in his discussion of the term global citizenship, 'there will always be distinct communities of state or nonstate definition dividing humanity into sometimes competitive subgroups' (Spiro 2020: 153).

Discussions on the consequences, both good and bad, regarding the eligibility criteria in both codes of rugby on players and national federations depend on whose perspective is considered - that of the player abroad or that of the receiving nation. For some players, the lenient eligibility criteria provide more opportunities to play at the international level. This applies, for example, to rugby league players in Australia who have foreign ancestry, or rugby union players from the Pacific Islands who play abroad and have the option to qualify via residence for other national teams.

When Lebanon qualified for the first time for the rugby league World Cup in 2000, the sport did not yet exist in Lebanon. Later, rugby league gradually developed, and in 2018 there were approximately 1,000 players in the country, around $0.13 \%$ of the global player pool. More than $60 \%$ of rugby league players worldwide, around 500,000 out of 800,000 , practice the sport in Australia, most in the provinces of Queensland and New South Wales (Reiche 2019). A closer look at Lebanon's squad at the 2017 rugby league World Cup confirms that a vast majority of the Lebanese players were not 'good enough' 
for the Australian national team. Apart from a few stars from the Australian National Rugby League (NRL), 'most of the squad are part-time players,' playing in lower-tier leagues (Woods 2017). Without Lebanese ancestry, these players would never have had the opportunity to play on a national team and to participate in the World Cup. Thus, presenting a case of the benefits players receive from the lax eligibility criteria. Regarding New Zealand rugby union players competing for other countries, Harris (2010: 75) also notes that 'in many cases, it could be argued that they would never have achieved international honours in their home nation.'

In rugby union, there is a growing presence of Pacific Islanders at the international level. According to Horton (2012), Pacific Islanders from the three major rugby-playing islands - Fiji, Samoa, and Tonga - have become the most prevalent ethnic group of rugby sports migrants globally, a process that is mainly socio-economically driven. One of the main purposes of migration for these players is to be able to remit money back home. From the perspective of professional leagues, in developed countries the rationale to recruit Pacific Islanders is that these players are comparatively inexpensive and equally talented. In contrast to rugby league players from Australia who qualify by ancestry to play for Lebanon, Pacific Islanders often qualify by residence after moving to professional clubs in countries such as France and Japan or to colleges in the United States.

The Pacific Islands rugby union federations are negatively affected by the eligibility criteria in rugby union. While the residency rule is certainly to their disadvantage, for players moving to economically stronger countries with professional leagues and college scholarships, the ancestry rule benefits them. There are many examples of expatriate Pacific Islanders in Australia and New Zealand looking for a country to represent (Overton et al 2011). According to their data, New Zealand outnumbered all other countries as the birthplace of 68 players at the 2011 World Cup, many of whom played for Samoa, Tonga, and Japan. The authors conclude that there is a 'complex geography that extends well beyond the rhetoric of simple player poaching and a rich/poor divide' (Overton et al. 2011: 100). Harris (2010: 84) made a similar observation about the 2007 rugby union World Cup: 'Despite the widespread criticism of their so-called pillaging of the South Sea Islands to strengthen their national team, there were more athletes born in New Zealand playing in the 2007 World Cup than there were from any other country.'

According to Harris (2010: 110):

Recruiting players born outside the country became a key feature of rugby in the professional era. While this had always happened in the amateur game with the advent of professionalism this became a more strategic initiative on the part of many unions and also reflected the increasing internationalisation of the sport within and between certain nations. 
An article on Fijian rugby labor migration published in 2013 estimated that at the time there were around 450 elite players from Fiji involved in foreign competitions (Kanemasu - Molnar 2013). For the authors, there is a counter-hegemonic potential of sport labor migration that gives players from the Fijis the dual opportunity to challenge marginalisation and to promote their home country on international fronts. For Kanemasu and Molnar there is a 'symbolic dimension of rugby migration as a medium to challenge the dominant Western discourse that defines Fiji and the other Pacific Islands as the ultimate "periphery" - small, remote, poorly resourced and dependent on Western largess for survival' (Kanemasu - Molnar 2013: 731).

While the aforementioned examples of players demonstrate how they benefit from the eligibility criteria in both codes of rugby, some domestic players are however disadvantaged by the rules when it comes to opportunities to represent their countries at the international level. Sakata (2004) investigated the influence of foreign players on Japanese rugby. Starting in 1985, the Japanese Rugby Union Federation (JRFU) began selecting foreign players for the national team, with the positive outcome of qualifying for every World Cup since 1987. However, the author of the article concluded that the strengthening of the national team with the use of foreign players came at the expense of developing young domestic players. 'Imported players have come to dominate key positions such as number eight and center, a trend often called "positional stacking". This deprives home-grown talent of opportunities and is therefore detrimental to the overall development of the national team' (Sakata 2004: 125). For Harris (2010: 108), 'notions of "sameness" become increasingly visible as migrant workers take their skills from country to country.'

The lenient eligibility criteria in both codes of rugby also change dynamics inside the teams. Within the Lebanese rugby league national team, English rather than Arabic is the working language, and the website of the federation is in English only (Reiche 2019). The team language in both codes has become English, and this applies not only to developing countries. Within the German rugby union team, for example, English and not German is the working language, as the author learned in conversation with the general director of the German rugby union, who said that this would be problematic for one German player who does not speak English.

In some countries, the diverse composition of the national teams is critiqued harshly. One example is France. At the rugby union World Cup in 2011 France was a 'largely self-sufficient country' with only two out of 31 players from abroad (Overton et al., 2011: 99). The team composition significantly changed over the following years, however, and at the 2015 rugby union World Cup 10 out of 31 French players did not have a French passport (Americas Rugby News 2015).

National federations ultimately decide the selection of players. Though they must respect the rules of the international federations, they have the final say 
when it comes to the rules' application. The rugby historian who was interviewed for this work emphasized that some countries are ignoring the reality of player mobility and globalisation: 'England just nominates players that play in England and not in neighboring France, for example. Southern hemisphere national teams do not nominate players from northern hemisphere clubs.'

The French rugby union federation announced the following in December 2016: 'From now on players who are not French nationals can no longer play for France. It's that simple. One will have to be in possession of a French passport to be considered for selection' (World Rugby 2016). The newly elected president of the French rugby union federation, Laporte, claimed the reason for the new policy is what he described as 'a political decision' and expressed his worries about the effect of the residency rule on other countries and the sport in general: 'One must not impoverish the Fijians, Georgians, Samoans, and Tongans; otherwise, we impoverish the standard of international rugby.' However, the magazine World Rugby commented that the decision 'is likely to please the majority of French rugby fans': 'The French would prefer their own countrymen to be wearing the blue jersey.' The new policy, which will not apply to those foreigners already selected to play for France, would require players to demonstrate a much deeper commitment to their new home country: 'To apply for French citizenship one needs to have lived in France for five continuous years and demonstrate a competency in the language and a knowledge of the culture' (World Rugby 2016).

The vice chairman of World Rugby, Augustin Pichot, stimulated a broad debate in November 2018 when he tweeted the percentages of foreign players in international friendlies. Pichot is from Argentina, and his home country was at the bottom of the list with zero percent non-national players. In a press interview Pichot said, 'Is the international game under threat? I think it is. Look at the balance sheets of some nations and you can see exactly where we stand' (Brooke 2018). In The Sydney Morning Herald, Robinson criticised Pichot's list in that it did not recognise that many Argentinian players have been trained by foreign systems. Furthermore, she argued that 'notions of nationality and identity are hard to pin down' as 'identity was something different for everyone':

The issue looks different from every angle, not least from a country like Australia, where almost 30 per cent of the resident population was born overseas. The Wallabies' 23 that beat New Zealand in the Indigenous jersey last year reflected that statistic (34 per cent), including that intolerable 'Plastic Aussie' Stephen Moore (born in Saudi Arabia). Should a Test nation stack its team full of three-year imports? No. Should Pichot get his facts right and frame the issue in a manner befitting his influential role in the global game? Absolutely (Robinson 2018). 
There was also a critical debate about foreign players on national teams around the 2017 rugby league World Cup. Gorman commented in an article in The Guardian:

Opinion is divided between those who believe these rules turn the tournament into a gimmick, and those who believe they are essential to grow the game internationally. Many of the nations that have qualified for this year's tournament are filled with Australians (Gorman 2017).

Collins presented a more positive view in a commentary for the website Conversation:

The RLIF decision reflected the fluidity of national identity today. As immigration and movement across national boundaries increases, national and regional identities become changeable and multi-layered... The 2017 World Cup and its diaspora national sides may well point the way to a new model for international representative sport in the twenty-first century. (Collins 2017)

Table 3 summarizes the consequences of allowing non-citizens to play in national teams for governments, fans, players, national and international federations.

\section{Table 3: Consequences of allowing non-citizens to play in national teams on different stakeholders}

\begin{tabular}{|l|l|}
\hline Stakeholder & Consequences \\
\hline Governments & - Less control on who represents country \\
\hline Fans & - Issues around identification discussed \\
\hline \multirow{3}{*}{ Players } & $\begin{array}{l}\text { - More options for some players at international level } \\
\text { - Fewer opportunities for home-grown talents ('positional stacking') } \\
\text { - English becoming working language of national teams } \\
\text { - No Olympic eligibility (rugby union) }\end{array}$ \\
\hline - Integrity publicly questioned
\end{tabular}




\section{Conclusion}

This article has shown that the main pillars of contemporary eligibility criteria in both codes of rugby, particularly the controversially discussed residency rule, are rooted in the history of the game and go back to the late $19^{\text {th }}$ century when first matches between countries took place. However, the rational for keeping the rules are different from the reasons for their introduction. While the original idea was to give exchange students from Commonwealth countries at English universities and migrants within the home nations (England, Scotland, Wales, and Northern Ireland) the opportunity to play where they stay, both showcasing a shared British imperial identity at that time, today's rational is different. Both the residence and the heritage rule are followed to maximize the limited global spread of rugby league and rugby union. Without these lenient rules it would be difficult to organize international competitions. This particularly applies to rugby league with its Australian hub, but also to the more globalized game of rugby union that is, although being readmitted to the Olympics since 2016 with its shortened version of rugby sevens, especially struggling to grow on the most populous continent, Asia.

This research has also shown that the effects of the eligibility criteria go beyond simplistic rich/poor and center/periphery models. This relates to the fact that there are two options by which a player can represent a country for which s(he) has no passport: ancestry, which especially benefits poor or war-torn countries with large diasporas, and residence, which primarily benefits developed countries with strong professional leagues.

While one could argue that the potential of sports to unite populations and strengthen national pride is hurt by diverse teams consisting of non-national players, a counter argument would be that the selection of the best available players regardless of passport is a showcase of meritocracy that also takes the increased mobility of people in globalised times into consideration. This practice might also contribute to increased understanding between nationals and foreign residents who have, for example, a different skin color or religion. The fact that they are all represented by the same national team might help subdue an 'us vs. them' mentality, prevalent in many countries.

In some people's perceptions, there may always be a hierarchy of 'real' above 'fake' national representatives. As long as nationality matters in international sport, these debates will continue. However, there is no longer anything like a 'pure' national team. As Nederven Pieterse writes in his book on globalization: "In a historical sense we are all migrants because our ancestors have all travelled the places where we have come from. States that impose border controls may go way back in time but their spread dates only from the nineteenth century and their covering the globe is more recent still" (Nederveen Pieterse 2015: 36). This sentiment is reflected in both codes of rugby. Most countries rely either on 
immigrants or their diasporas for talent. And even in the case that all players of a national team are born in the country they represent, they may have (grand) parents from elsewhere or may have benefitted from playing in stronger leagues abroad, making them also products of globalisation.

\section{References}

Americas Rugby News (2019): 'Foreign-born Players at RWC 2019', (7 September 2020): available at: http://www.americasrugbynews.com/2019/09/09/foreign-born-raised-players-at-rwc-2019/.

Americas Rugby News (2015): 'Foreign-born Players at RWC 2015', (9 February 2019): available at: http://www.americasrugbynews.com/2015/09/13/foreign-born-players-rwc-2015/.

Bale, John, and Maguire, Joseph. (Eds.). (2013): The global sports arena: Athletic talent migration in an interdependent world. Routledge.

Bengtsson, Bo. (2012): "Path Dependency." In Smith, S. J. (2012). International encyclopedia of housing and home. Elsevier, (7): 161-166.

Bohland, J. D. (2017): Who Counts as a Real American? Dual Citizenship, Hybridity, and the US Men's National Team in Football and the Boundaries of History, Palgrave Macmillan, New York, p. 179-202.

Brooke, C. (2018): Some are Calling for Augustin Pichot to Resign Over Controversial Tweet. Rugbypass, (9 February): available at: https://www.rugbypass.com/news/some-are-calling-for-augustin-pichot-to-resign-over-controversial-tweet.

Bryman, Alan. (2012): Social Research Methods: OUP Oxford.

Chiba, Naobi, and Jackson, Steve J. (2006): Rugby player migration from New Zealand to Japan. Football Studies 9(2): 67-78.

Collins, Tony. (2009): A social history of English rugby union. Routledge.

Collins, Tony. (2013): Rugby's great split: Class, culture and the origins of rugby league football. Routledge.

Collins, Tony. (2017): 'How Rugby League's Relaxed Rules for Diaspora Players Gave the Sport a New Lease of Life', Conversation (9 February, 2019): available at: https://theconversation. com/how-rugby-leagues-relaxed-rules-for-diaspora-players-gave-the-sport-a-new-lease-of-life-88104.

Cronin, Mike, and Mayall, David, ed. (2005): Sporting Nationalisms: Identity, ethnicity, immigration and assimilation. Routledge.

Dolan, Paddy, and Connolly, John (2016): Sport, Unity and Conflict: An enduring social dynamic. European Journal for Sport and Society 13(3): 189-196. 179-202. Available at: https://doi.org /10.1080/16138171.2016.1229836.

Exner, Jan (2019): Sporting Nationality in the Context of European Union Law: Seeking a Balance between Sporting Bodies' Interests and Athletes' Rights. Springer. 
Gorman, Joe (2017): 'Lebanon's World Cup is About More Than Simply Rugby League', The Guardian (9 February, 2019): Available at: https://www.theguardian.com/sport/2017/oct/20/ lebanons-world-cup-is-about-more-than-simply-rugby-league.

Grainger, Andrew (2006): From immigrant to overstayer: Samoan identity, rugby, and cultural politics of race and nation in Aotearoa/New Zealand. Journal of Sport and Social Issues 30(1): 45-61. Available at: https://doi.org/10.1177/0193723505284277.

Grainger, Andrew, Rick, Oliver, J., \& Andrews, David, L (2014): Bound to the nation: Pacific Islands rugby and the IRB's new 'one-country-for-life' eligibility rules. Sport in Society 17(7): 977-991. Available at: https://doi.org/10.1080/17430437.2013.806035.

Guinness, Daniel, and Besnier, Niko (2016): Nation, Nationalism, and Sport: Fijian Rugby in the Local-Global Nexus. Anthropological Quarterly, 1109-1141. Available at: https://doi.org/10.1353/ anq.2016.0070.

Harris, John (2010): Rugby union and globalization: An odd-shaped world. Springer.

Horne, John, Tomlinson, Alison, Whannel, Garry, and Woodward, Kath (2012): Understanding sport: A socio-cultural analysis. Routledge.

Horowitz, John, and McDaniel, Stephen. R. (2015): Investigating the global productivity effects of highly skilled labour migration: How immigrant athletes impact Olympic medal counts. International journal of sport policy and politics 7(1): 19-42. Available at: https://doi.org/10. 1080/19406940.2014.885910.

Horton, Peter (2012): Pacific Islanders in global rugby: The changing currents of sports migration. The International Journal of the History of Sport 29(17): 2388-2404.

International Cricket Council (2018): 'Player Eligibility Regulations. Effective as from October 2018.' (21 September, 2020): Available at: https://www.icc-cricket.com/about/cricket/rules-and-regulations/playing-conditions.

International Netball Federation (2016): 'General Regulations. Effective November 12016.'

(21 September, 2020): Available at: https://netball.sport/wp-content/uploads/2016/11/INF-General-Regulations-November-2016.pdf.

IOC (2018) 'Olympic Charter.' (9 February, 2019): Available at https://stillmed.olympic. org/media/Document\%20Library/OlympicOrg/General/EN-Olympic-Charter.pdf\#_ ga=2.227061471.314482763.1542921705-566241420.1542921705.

IRFB (1892): 'Minutes of the IRFB board meeting from July 7, 1892.'

Jansen, Joost, and Engbersen, Godfried (2017): Have the Olympic Games become more migratory? A comparative historical perspective. Comparative migration studies 5(1): 11.

Jansen, Joost, Oonk, Gisbert, and Engbersen, Godfried. (2018). Nationality swapping in the Olympic field: towards the marketization of citizenship? Citizenship Studies 22(5): 523-539. Available at: https://doi.org/10.1080/13621025.2018.1477921.

Johnes, Martin (2000): Eighty minute patriots? National identity and sport in modern Wales. The International Journal of the History of Sport 17(4): 93-110. Available at: https://doi. org/10.1080/09523360008714148. 
Kanemasu, Yoko, and Molnar, Gyozo (2013): Pride of the people: Fijian rugby labour migration and collective identity. International Review for the Sociology of Sport 48(6): 720-735. Available at: https://doi.org/10.1177/1012690212453655.

Kivisto, Peter (2018): Citizenship: T.H. Marshall and Beyond in Outhwaite, William, and Turner, Stephen, J. ed. (2017): The SAGE Handbook of Political Sociology, 2v. Sage.

Lakisa, David, Adair, Daryl, \& Taylor, Tracy (2014): Pasifika diaspora and the changing face of Australian Rugby League. The Contemporary Pacific, 347-367. Available at: 10.1353/cp.2014.0029

Maguire, Joseph., \& Tuck, Jason (1998): Global sports and patriot games: Rugby union and national identity in a united sporting kingdom since 1945. Immigrants \& Minorities 17(1): 103-126. Available at: https://doi.org/10.1080/02619288.1998.9974931

Markovits, Andrei. S., \& Rensmann, Lars (2013): Gaming the world: how sports are reshaping global politics and culture. Princeton University Press.

Pieterse, Jan, N. (2015): Globalization and Culture: Global Mélange. Rowman \& Littlefield.

Overton, John, Murray, Warwick, E., and Heitger, Jo. (2013). Pass the passport! Geographies of the Rugby World Cup 2011. New Zealand Geographer 69(2): 94-107. Available at: https://doi. org/10.1111/nzg.12013.

Poli, Raffaeli (2007): The denationalization of sport: De-ethnicization of the nation and identity deterritorialization). Sport in Society 10(4): 646-661. Available at: https://doi. org/10.1080/17430430701388798.

Pienaar, Sare, J., and Koch, Karen (2012): Antecedents influencing rugby migration in South Africa.

Price, Steve (2020): 'FIFA Eligibility Rule Change Offers World Cup Hopes For ‘One-Cap Wonders", Forbes (19 September 2020): Available at: https://www.forbes.com/sites/steveprice/2020/09/19/fifa-eligibility-rule-change-offers-world-cup-hopes-for-one-cap-wonders/?sh=3b913810511e.

Reiche, Danyel, and Tinaz, Cem (2019): Policies for naturalisation of foreign-born athletes: Qatar and Turkey in comparison. International Journal of Sport Policy and Politics 11(1): 153-171. Available at: https://doi.org/10.1080/19406940.2018.1528994.

Reiche, Danyel (2018): The Role of the Lebanese-Australian Diaspora in the Establishment of Rugby League in Lebanon. The International Journal of the History of Sport 35(5): 448-467.

RLIF (2016): “3 Eligibility for International Rugby League (9 February 2019): Available at http:// www.rlif.com/ignite_docs/20160920\%20RLIF\%20Eligibility\%20Rules\%20-\%20Final.pdf.

Sakata, Hiroshi (2004): 'The influence of foreign players on the transformation of Japanese rugby over the last three decade,' (9 February 2019): Available at https://ir.canterbury.ac.nz/ bitstream/handle/10092/2277/Thesis_fulltext.pdf?sequence=1\& isAllowed=y.

Schroeder, Pete, \& Janssen, Chriss (2012): Sport Labour Migration: Managing a twenty-first-century global workforce in Managing Sport: 169-192. Routledge.

Spiro, Peter, J. (2016): 'At Home in Two Countries: The past and future of dual citizenship.' NYU Press, Vol. 11.

Spiro, Peter, J. (2020): 'Citizenship: What Everyone Needs To Know.' Oxford University Press. 
Wigmore, Tim (2016): 'Playing Rugby, Representing... Multiple Countries', The New York Times (9 February 2019): Available at: https://www.nytimes.com/2016/10/28/sports/rugby/nationality-rule-change.html.

Woods, Dave (2017): 'Rugby League World Cup 2017: How Has the Sport Become So Popular in Lebanon?' BBC (9 February 2019): Available at: https://www.bbc.com/sport/rugby-league/41805294.

World Bowls (2018): Regulations in full. (21 September 2020): Available at: http://www.worldbowls.com/about-us/regulations-in-full/.

World Rugby (2016): “Regulation 8." (9 February 2019): Available at: https://www.worldrugby. org/wr-resources/WorldRugbyDIR/Handbook/English/pubData/source/files/Regulation8.pdf.

World Rugby (2019): 'RWC 2019 sets new broadcast records and inspires new audiences', (7 September 2020): Available at: https://www.rugbyworldcup.com/news/564996\#: :text=Those\%20 impressive\%20figures\%20helped\%20to, cent\%2C\%20or\%20172\%20million\%20viewers.

World Rugby (2020): ‘Regulation national team representation (COVID-19 residency criteria adjustment)', (27 June 2021): Available at: https://www.world.rugby/news/579716/regulation8-national-team-representation-covid-19-residency-criteria-adjustment.

World Squash Federation. 'World Squash Championship Regulations. 1December 2019,' (21 September 2020): Available at: http://www.worldsquash.org/wp-content/uploads/2019/11/191201_ Championship-Regulations-V9.0.pdf.

Danyel Reiche is a Visiting Associate Professor at Georgetown University Qatar. He is on leave from the American University of Beirut in Lebanon where he is a tenured Associate Professor of Comparative Politics. His past research has focused on two areas: energy and sport policy and politics; the latter his recent priority. He published Success and Failure of Countries at the Olympic Games in 2016 with Routledge and edited with Tamir Sorek a volume entitled Sport, Politics, and Society in the Middle East (Oxford University Press). Email: dtr38@georgetown.edu. 